\title{
On the structural barriers to public innovation support for SMEs and the opportunity COVID-19 can offer to overcome these barriers
}

\author{
Matthias Deschryvere \\ matthias.deschryvere@vtt.fi | VTT Technical Research Centre of Finland, Vuorimiehentie 3, Espoo \\ Finland. \\ Markku Mikkola \\ markku.mikkola@vtt.fi |VTT Technical Research Centre of Finland, Vuorimiehentie 3, Espoo Finland. \\ Steffen Conn \\ conn@ispim.org | International Society for Professional Innovation Management (ISPIM)

\section{Letter from Academia}

\begin{abstract}
COVID-19 pandemic-related direct public support mechanisms have received more attention than previously and budgets for SME subsidies have skyrocketed around the globe. Currently, most support measures focus on short-term liquidity needs. However, policy makers have already started thinking about which role subsidies should play in the renewal of the economic structure once the pandemic dust has settled. The pandemic offers a good opportunity to restructure a company support system taking into account the structural barriers that innovation support systems have been subject to over the last decade. The aim of the analysis in this letter is threefold: (1) to map the barriers to innovation support, (2) to offer policy makers and SME support agencies a set of solutions to overcome these barriers and (3) to re-interpret these results against the background of the COVID-19 pandemic that started to unravel shortly after finalising the set of research interviews.
\end{abstract}

Keywords. Innovation Policy; Public Support; R\&D Subsidies; Structural Barriers; Small and Mediumsized Enterprises; SME; COVID-19.

Cite paper as: Deschryvere, M., Mikkola, M., Conn, S., (2020). On the structural barriers to public innovation support for SMEs and the opportunity COVID-19 can offer to overcome these barriers - Letter from Academia, Journal of Innovation Management, www.open-jim.org, 8(2), 16-25. 


\section{Introduction}

Since the outbreak of the pandemic, direct public support mechanisms have received more attention than previously and budgets for SME subsidies have skyrocketed around the globe (e.g. VNK, 2020; OECD, 2020). Currently, most support measures focus on short-term liquidity needs. However, policy makers have already started thinking about which role subsidies should play in the renewal of the economic structure once the pandemic dust has settled (e.g. EIT, 2020). Given the hasty launch to firms of a number of brand new support instruments that were badly designed and poorly implemented, in certain countries a debate has already started on the clear need to restructure the company subsidy system. Eventually, budgetary constraints will become tighter and calls for restructuring company support systems around the world will grow more pronounced.

When restructuring the support system for firms, primary attention should be paid to innovative firms as they can set the stage for entirely new industries and spur the renewal of existing industries, ultimately driving long-term economic growth. Moreover, the latest evidence on the impact of different innovation support instruments should offer solid guidance when designing a balanced policy mix for innovation policy that has the greatest impact (Bloom et al. 2019).

Innovation policy makers and innovation support agencies have been facing a set of structural barriers that prevent them from making more impact. The pandemic offers a good opportunity to restructure the company support system taking into account the structural barriers that innovation support systems have been subject to over the last decade.

This letter is based on a policy brief document that was published in May 2020 as Deliverable 5.5 in the H2020 SMEthod project (project number 777491). The analysis is based on semistructured interviews with 16 representatives of $11 \mathrm{EU}$ and UK innovation support agencies and policy makers. The interviews were conducted during the last quarter of 2019. In this discussion paper we depart from the results of the policy brief document and re-interpret them against the background of the ongoing pandemic. The aim of the analysis is threefold: (1) to map the barriers to innovation support, (2) to offer a set of solutions to policy makers and SME support agencies to overcome these barriers and (3) to re-interpret these results against the background of the COVID-19 pandemic that started to unravel shortly after finalising the set of interviews.

This letter contributes to the literature on innovation barriers by focusing on the barriers that are faced by public support actors in offering innovation support to innovative firms. Most evidence in the literature on innovation barriers is based on micro-level survey evidence from firms. Examining the barriers that are faced by support agencies has the advantage that their complementary evidence is situated on the macro-level as it bundles information from a wide range of firms over time. Most importantly, the identified barriers are complemented with recommendations on how to solve them and their validity has been checked against the background of the unravelling pandemic.

The discussion paper first presents the identified barriers (Chapter 2) after which potential solutions (Chapter 3) and the effects of COVID-19 on the barriers (Chapter 4) are discussed. The letter concludes with a discussion on the way forward (Chapter 5). 


\section{Structural barriers to innovation support}

The most severe and long-term challenges faced by public organisations supporting SME innovation are situated at the SME end - in other words - on the demand side of support. It is access to talent that sets the stage for which kind of SMEs can be developed and which kind of growth path can be attained (Kerr, 2020). Concerning the access to talent that SME teams have, the support agencies and policy makers that were interviewed identified three main barriers: (1) SME teams are not ambitious enough; (2) SME teams are not diverse enough and; (3) valuable innovation activities are concentrated into increasingly fewer firms and these rising innovation disparities are associated with rising inequality.

As well as the three concerns noted by innovation support actors about their SME customers, the analysis identified seven barriers on the supply side of support. At the meso level, the innovation support organisations themselves need resources to continuously renew their capabilities in a fast-changing world, as well as additional funds for the implementation of new policies and instruments. At the macro level, policies and instruments need to be stable and predictable. However, new instruments can be introduced if they are able to cover new or existing support gaps and are suitable for tackling the grand challenges faced by EU countries. Cooperation between support actors from the public and private sector can be encouraged by new instruments and cooperation structures for raising matched funding, and the overall public support system would benefit from a user-friendly simplification (e.g. Veugelers, 2009).

\section{Solutions to overcome the barriers}

The following sub-chapters briefly present our recommendations to overcome the structural barriers to innovation support that we identified.

\section{Foster motivation and attitudes to boost the ambition of SME teams}

To encourage economic growth, the ambition level of SME teams should be more explicitly acknowledged by policies. One way to achieve this is to promote ambition as one of the key criteria for SME support in all EU countries. Another way of addressing ambition is to give innovation and growth opportunities to both innovative and non-innovative SMEs.

\section{Forge new SME teams to rectify the lack of diversity and talent}

Policy instruments should focus on building capabilities, forging strong teams and accessing both EU and non-EU talent (e.g. Coad et al., 2020). Moreover, developing an innovation system that focuses on long-term capability building will help companies be prepared for shocks. A collaborative long-term model that focuses on capability development is exactly the kind of shockabsorbing model that could accommodate today's turbulent times. In order to know precisely which programmes and instruments should be developed, a roadmap for capability development should be created that analyses the various set of skills that will be needed in the future. In turn, stronger teams can be built by creating larger national and international pools of diverse human resources using digital matching platforms. To access foreign talent, new programmes can be developed that target specific sets of skills in specific countries, such as the 'Talent Boost' 
programme in Finland. While typical talent attraction models aim to attract people, the main aim is to have virtual access to talent - and this does not necessarily require people to move or travel. However, talent access via virtual teams may only be viable for larger SMEs and SMEs that are lead users in digitalisation practices.

Focus on both innovation leaders and followers in order to limit the disparities inherent to innovation

All instruments for innovation support should acknowledge the heterogeneity of a firm's capabilities and its sectoral and regional specificities. The focus on regions with less known innovative SMEs should be on establishing new firms and stimulating the development of new innovative firms. Regional characteristics could become increasingly important SME segmentation criteria, while keeping in mind that the selection pool for public funding should be of sufficient size to maintain an optimal level of competition. As the tension between innovation policy and regional policy is omnipresent, it is important to be transparent about where and why the precise border between policy areas is drawn.

\section{Monitor and close all important gaps in SME development support}

The policy focus should continue to be on innovation ecosystem development and on how large firms can help small and young firms to scale-up (cf. Knockaert et al., 2019). This also means that innovation support organisations should acknowledge the innovation ecosystem dimension as a relevant segmentation dimension in their innovation support models (e.g. Kreutzer, 2018). This is certainly not the case yet in all EU countries.

\section{Reduce the complexity of the support system with client-orientated approaches}

The support service system should be truly designed with the client and implemented for the client. Firstly, this requires a simple interface for SMEs that is characterised by unification of the service processes. Secondly, this requires CRM systems that minimize the need for data inputs and maximize data sharing based on optimal permits. Thirdly, this requires intelligent service offerings, based on client needs information and AI solutions. Fourthly, this requires a simplification of business support by fostering complementarities between different support services instead of competition between service providers.

\section{Match public funding with sufficient private funding}

Public-private partnerships to fund SMEs transitioning from the start-up phase to the scale-up phase should be further promoted. Using funds of funds could be one viable way of implementing public-private joint investment activities.

\section{Ensure the stability of policy and instruments}

The predictability of policy and instruments should be safeguarded in order to build trust in the long-term funding environment for innovation investments. This does not mean that changes should be abandoned altogether but rather that changes in policies and instruments are made in a predictable and transparent manner. Finding the balance between stability and agility is important because they are both important cornerstones conditional for the resilience of an innovation system. 


\section{Reserve sufficient resources for policy implementation}

For implementation, sufficient resources must be set aside in terms of a budget for personnel and cooperation with other agencies. In the case of the implementation of new innovation policy in particular, the development of operational procedures requires cooperation between different agencies. The design of new policies and instruments should take this additional budgeting into account and such an approach will also benefit the predictability of policies.

\section{Have a concrete plan on how to support the grand challenges}

All innovation support agencies must have clarity on how they are going to contribute to solving the grand challenges and how they are going to monitor their progress in this respect. New data will need to be collected and new methodologies and ways of thinking will need to be developed. The segmentation of SMEs should consider the impact the SMEs are seeking by paying consistent attention to the grand challenges that the firms are addressing via their innovations.

There is a need for R\&D funding for the United Nations Sustainable Development Goals (UN SDGs) and market creation (via programmes) and public-private partnerships. The downside is that policy makers may earmark money for new programmes, which could lead to quick spending.

\section{Invest in skills development in support ecosystem}

Firm development requires knowledge about private investors and their networks. To enable this, face-to-face contacts with the entrepreneurial teams that run the firms would be crucial. The automation of funding decisions typically misses the outliers and it is exactly those firms that can turn out to be very valuable. However, the automation of decision-making could be a promising avenue for smaller grants thus freeing resources for the skills that require support tasks.

\section{Discussion on how COVID-19 will affect the structural barriers to innovation support}

Our expectations on how the identified barriers to innovation support for SMEs will be affected are summarized in Table 1. The identified barriers offer a useful framework for considering what opportunities and what threats the pandemic could represent to innovation support and the innovation system. We see a further increase in the relevance of most of the identified barriers during the crisis but believe that restructuring the public support landscape also offers bright opportunities. Restructuring the support system could be more robust if the identified barriers to innovation support are considered.

As the economic headwinds triggered by the pandemic are picking up, the teams in charge of SMEs will need to be more ambitious in order to survive and grow. This suggests that a lack of ambition could be a greater barrier than before the current crisis. As lower activity levels in SMEs may constitute a real threat to the depreciation of human capital and motivation, at both entrepreneur level and employee level, it is important that sufficient investments are made in capability building. This is the perfect opportunity to invest in digital skills or to experiment 
Table 1. Expected effects of COVID-19 on the identified barriers to public innovation support for SMEs

\begin{tabular}{|c|c|}
\hline Barriers & Expected impact of COVID-19 \\
\hline \multicolumn{2}{|c|}{ Demand side of public innovation support } \\
\hline 1 Lack of ambition & Need for ambition will increase \\
\hline 2 Lack of diverse teams & Need for diversity will increase \\
\hline 3 Rising disparities in innovation & Inequalities will increase \\
\hline \multicolumn{2}{|c|}{ Supply side of public innovation support } \\
\hline 4 Gaps in support & Resources will be more constrained \\
\hline 5 Complexity of the support system & Good opportunity to simplify \\
\hline 6 Lack of matching private funding & Need for cooperation will increase \\
\hline 7 Lack of stability in policies & Leadership needed \\
\hline 8 Lack of resources for policy implementation & Currently highly relevant \\
\hline 9 Supporting grand challenges & $\begin{array}{l}\text { Affects many of the United Nations Sustainable } \\
\text { Development Goals }\end{array}$ \\
\hline $\begin{array}{l}10 \text { Lagging skills development in the support } \\
\text { ecosystem }\end{array}$ & Take a leap forward in digital skills \\
\hline
\end{tabular}

with completely new ideas. This capability building in SMEs should now be one of the key focus areas of the public support system.

The need for diverse teams will become more important as diverse teams can foster performance (cf. Korn Ferry, 2018). However, it is not clear how the crisis will affect the mobility of people who could be restricted by country-specific limitations for a long time to come. Once borders have started to reopen, the regions that have recovered faster from the Covid-19 shock will be more likely to succeed in talent attraction. However, it can be expected that in the short to midterm, the mobility of people will be lower and the challenge to increase diversity will become greater.

The main concern regarding the current crisis lies in its power to raise inequality and there are now signs that the pandemic has led to a series of inequality shocks (Adams-Prassl et al., 2020a/2020b). While there was already evidence of innovation disparities before the crisis (OECD, 2019), we can expect this trend to pick up during and after the crisis with the danger that the image of innovation will become increasingly negative as more regions start to lose out. In this respect, it is crucial to keep on searching for the balance and keep on believing in the power of innovation as a way of increasing prosperity in society.

The landscape of innovation agencies would benefit from a simplification and the crisis offers a good opportunity to plan and implement a restructuring. However, a restructuring should not be driven by short-term cost cutting or emergency actions. Instead, it should be used to make the system truly stronger and better. Restructuring should also address how important support gaps will be covered as it can be expected that there will be more financing gaps. Restructuring 
should also consider a reserve budget for the implementation of changes and new instruments. This may become one of the critical bottlenecks.

While the crisis can be an opportunity to restructure and make the system better, this cannot be achieved without real leadership that ensures a sufficient level of policy stability as this is often a condition for private $R \& D$ investments to be approved. There is a threat that instability in policies may increase due to the rapid introduction of new policies and instruments to manage the emergency. Given the challenges that lie ahead, the need for cooperation between the public and private sector will increase and it is crucial that both public and private funds work together in forging a way out of the crisis. The main aim of public sector support is to encourage the private sector to survive and start to invest again, eventually.

Grand challenges remain but the speed at which they are tackled decrease. The COVID-19 crisis has directly or indirectly been affected by several Sustainable Development Goals of the United Nations (UN SDGs) and it can be expected that more concrete actions will be needed to tackle these. A clear uncertainty resulting from the pandemic is that competition between the goals has been rising and that climate change actions, for example, have been affected by concerns about the pandemic. Regaining the balance here will be important if economic recovery is to happen.

Finally, yet importantly, the pandemic offers an opportunity to upgrade the capabilities of the innovation support actors. Taking into account the latest developments in fintech and digitalisation, support agencies can completely reinvent themselves and, for public players, now is the perfect time to invest in this infrastructure.

\section{Conclusions}

We see the COVID-19 crisis as a strong opportunity to tackle the 10 structural barriers to public innovation support we identified as it is investments in innovation that will need to put our societies back on track. This will require a well functioning innovation system with the right balance of instruments.

We would like to conclude this discussion paper by highlighting one key threat - that does not necessarily have to materialize - and one key opportunity, that hopefully will not be wasted.

One major threat is that the pandemic will be bad for innovation and will negatively impact private and public R\&D investments. This is a profound threat as it is precisely innovation that drives long-term economic growth. Private investments could suffer because negative demand shocks typically slow down turnover, profits and R\&D investments for firms that switch to survival mode.

Public investments could suffer because with crumbling budgets the focus of policy makers typically turns to short-term solutions and not to long-term counter-cyclical investments. However, there are a number of examples of counter-cyclical investments during crises, for example, how Germany picked up investments during the Great Recession. These brave decisions require leadership. In fact, the best way out of this crisis is to have a solid counter-cyclical investment plan for R\&D. 
One key opportunity is to use the crisis to restructure the innovation system and its public support pillar. The aim of such a reform should ultimately be to raise the capacity of the innovation system to absorb shocks. This requires optimal use of resources in order to build and foster the right kind of capabilities throughout the innovation system. Better access to capabilities will offer firms the best chances to succeed. While for many companies the demand is already too low, now is the best time for them to experiment and learn new capabilities. Restructuring the system should rebalance and simplify the policy mix with the ultimate aim of serving the client. Moreover, public support actors should update their knowledge of the latest developments and opportunities in terms of finance and digitalisation (e.g. Block et al. 2020).

To conclude, we underline four key trends that will drive the innovation policy and direct the innovation support agenda in the coming years - and that will all be affected by the crisis: (1) Solving grand challenges related to the United Nations Sustainable Development Goals is becoming mainstream (cf. Mazzucato, 2018). However, some of the key goals may unfortunately have to be put on hold due to the pandemic. (2) The borders of innovation policy will continue to become less clear due to the rising interaction with competition policy, industrial policy and regional policy. We foresee difficult times ahead for innovation policy with the borders between policy areas becoming even more blurred. (3) Smart specialisation will be important, although the focus has jumped from the poorer regions to the more powerful cities. The crisis will accelerate this divide and stimulate regions to become more self-sufficient (4) With shrinking budgets, the competition for innovation support will increase and it is important to ensure that the right segments of firms will receive the support they deserve for the revival of European society and the economy. This trend will magnify the need to segment the hugely heterogeneous group of SMEs more carefully in order to ensure that the right firms get the right level of support.

\section{Acknowledgements}

This letter was produced as part of a H2020 SMEthod research project (project number 777491). The authors would like to thank the consortium partners from ASM-Market Research and Analysis Centre Ltd. (Poland), University of Łódź (Poland), Lancaster University (UK), Cámara de Comercio, Industria y Servicio de Badajoz (Spain), The International Society for Professional Innovation Management Ltd. (UK) and Apintech (Cyprus) for their excellent collaboration in achieving these results.

\section{References}

Adams-Prassl, A., Boneva, T., Golin, M., Rauh, C. (2020a). Inequality in the impact of the Coronavirus Shock, new survey evidence for the UK. Mimeo.

Adams-Prassl, A., Boneva, T., Golin, M., Rauh, C. (2020b). Inequality in the impact of the Coronavirus Shock, new survey evidence for the US. Mimeo.

Block, J.H., Groh A., Hornuf L., Vanacker T., Vismara, S. (2020). The entrepreneurial finance markets of the future: a comparison of crowdfunding and initial coin offerings. Small Business Economics: https://doi.org/10.1007/s11187-020-00330-2 
Bloom N., Van Reenen J., Williams H. (2019). A Toolkit of Policies to Promote Innovation. Journal of Economic Perspectives, 33 (3), 163-84: https://pubs.aeaweb.org/doi/pdfplus/10.1257/jep.33.3.163

Coad, A., Mathew, N., Pugliese, E. (2020). What's good for the goose ain't good for the gander: heterogeneous innovation capabilities and the performance effects of R\&D. Industrial and Corporate Change, 29(3), June 2020, 621-644.

EIT (2020): EIT Crisis Response Initiative: https://eit.europa.eu/our-activities/covid-19-response/eitcrisis-response-initiative

Kerr, W.R. (2020). "The Gift of Global Talent: Innovation Policy and the Economy," Innovation Policy and the Economy, University of Chicago Press, vol. 20(1), pages 1-37.

Knockaert, M., Deschryvere, M., Lecluyse, L. (2019). The relationship between organizational interdependence and additionality obtained from innovation ecosystem participation, Science and Public Policy, 46(4), 490-503: https://doi.org/10.1093/scipol/scz002

Korn Ferry (2018). Future of work. The Global Talent Crunch: https://focus.kornferry.com/wpcontent/uploads/2015/02/The-Global-Talent-Crunch.pdf

Kreutzer, (2018). An integrated and effective Nordic ecosystem for innovation and green growth: A closer look at access to risk capital in the Nordic countries. https://www.norden.org/en/ publication/integrated-and-effective-nordic-ecosystem-innovation-and-green-growth.

Mazzucato, M. (2018). Mission-oriented research and innovation in the European Union. A problem-solving approach to fuel innovation-led growth. European Commission: https://op.europa.eu/ en/publication-detail/-/publication/5b2811d1-16be-11e8-9253-01aa75ed71a1/language-en

OECD (2020) OECD Survey on the science and innovation policy responses to coronavirus (COVID-19): https://stip.oecd.org/Covid.html

OECD (2019). Workshop on Innovation disparities: Summary of discussions. OECD Directorate for Science, Technology and Innovation, Committee for Scientific and Technological Policy, DSTI/STP/TIP(2019)18, 5 November 2019.

Veugelers et al. (2009). Evaluation of the Finnish National Innovation System: Policy Report. ETLA: https://www.etla.fi/wp-content/uploads/InnoEvalFi_POLICY_Report_28-Oct2009.pdf

VNK (2020). Koronakriisin vaikutukset ja suunnitelma epidemian hallinnan hybrydistrategiaksi, Exit- ja jälleenrakennustyöryhmän 1. vaiheen raportti, Valtioneuvoston Julkaisuja 2020:12 


\section{Biographies}
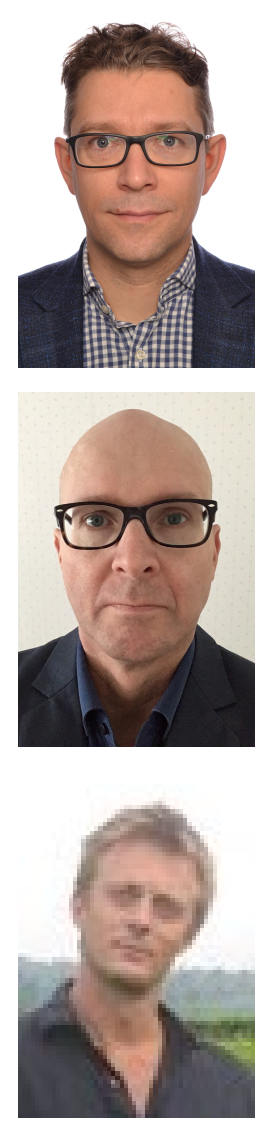

Matthias Deschryvere. Matthias Deschryvere works as a senior scientist and innovation economist at the Quantitative Science and Technology Studies team of VTT Technical Research Centre Finland Ltd. Deschryvere his work has been focusing on the role of innovation and diversity for the performance of firms, ecosystems and countries and on innovation policy design.

Markku Mikkola. Markku Mikkola has a MSc degree in industrial engineering and management from Lappeenranta University of Technology, Finland. He currently holds the position of senior scientist at VTT Technical Research Centre of Finland. His main research interests include business models and business process development especially in the areas of manufacturing and product \& service development. He has participated in several development projects in Finnish industrial companies and business networks including SMEs especially in the machine and electronics-manufacturing sector both as a researcher and project manager.

Steffen Conn. Steffen is Operations Director of the International Society for Professional Innovation Management (ISPIM), a network of researchers, industrialists, consultants and public bodies who share an interest in innovation management. He is responsible for the day-to-day operations of the Society as well as the growth of its Special Interest Groups and research engagement. Steffen has edited more than 20 journal special issues and books on innovation. He holds a Doctor of Science (distinction) from Lappeenranta University of Technology, Finland. 